\title{
Consumer Behavior Towards Foreign Versus Local Products and Brands: Future Research Directions
}

\author{
S Sulhaini \\ Department of Management \\ University of Mataram \\ Mataram, Indonesia \\ sulhaini@unram.ac.id
}

\begin{abstract}
This paper reviews five theories explicative of consumer predispositions towards foreign or local products and brands: social identity theory, personal identity theory, cultural identity theory, system justification theory, and categorical cognitive theory. This paper also identifies research questions and adjoining disciplines to propose future directions of research; these directions follow the research stream of consumer culture theory. Moreover, the paper proposes further studies of recent trends in the fourth industrial revolution and the (post-) COVID-19 pandemic setting. These research avenues are particularly noteworthy in the context of developing countries. They may lead to studies of each theory that are sharper, deeper, and more focused and allow the application of adjoining disciplines into consumer behavior studies, especially the consumer culture theory stream.
\end{abstract}

Keywords- consumer behavior, social identity, personal identity, cultural identity, system justification, categorical cognition

\section{INTRODUCTION}

Consumer behavior (CB) has been viewed as a subdiscipline of marketing. CB exists as a coherent set of actors, behaviors, and situations [1]. It is characterized by the study of people in their capacities as consumers, including the acquisition, consumption, and disposition - each of which may be shaped by various interconnected market forces - of products, services, and brands [2]. Macinnis \& Folkes [2] identified three streams of studies on $\mathrm{CB}$ : information processing, behavioral decision theory, and consumer culture theory (CCT). To a great extent, these streams are influenced by various disciplines that adjoin (but remain outside of) marketing, such as anthropology, sociology, psychology, linguistics, neuroscience. Nonetheless, Belk [3] argued that information processing and behavioral decision theory can be integrated into a single-stream termed consumer psychology (CP). Accepting such an integration, $\mathrm{CB}$ can then be delineated into two main streams, which are CP and CCT. The underlying and adjoining disciplines of the two streams vary [2]; however, some constructs present in one stream can be also recognized in, or regarded as constructs of, the other stream. Examples of this include emotion, desire, and imagination, which are claimed to be constructs of $\mathrm{CP}$ but also, because they are mediated by the culture, of CCT [4]. In $\mathrm{CB}$, a given construct can be evaluated and measured in both streams [5]. This may be a sign that the distinction between the two streams has been softened - the lines between them blurred - and pursuing one stream of research will likely involve constructs that are also investigated in the other stream. Therefore, it is fair to say that research on $\mathrm{CB}$ pieces of evidence intersections between the two streams and, at the same time, openness to the integration of various neighboring disciplines.

$\mathrm{CB}$ has been a dominant research topic in reputable international journals of marketing for 60 years, and it will continue to flourish in the future as the topic presents a high potential for innovation [6]-[7]. This continued flourishing will inevitably extend to the disciplines adjoining $\mathrm{CB}$, ultimately enriching our understanding of the theories of CB. The adjoining disciplines mentioned above provide opportunities for researchers to be innovative and productive in research and publication. Nonetheless, various authors [1][2]-[3] have stated that even though CB theory developing dynamically, it is not yet fully multidisciplinary and must become more open to supporting its development by importing and integrating knowledge from various disciplines. CCT is a growing research stream, and articles on $\mathrm{CCT}$ are the most cited in reputable journals of CB [7]. [8] argued that CCT is much like a family of theoretical perspectives that address the dynamic relationships between consumer actions, the marketplace, and cultural meanings, which can be influenced by globalization and market capitalism. They further argued that CCT explains CB by illuminating socio-cultural processes and structures in light of consumer-identity projects, marketplace cultures, sociohistoric patterns of consumption, and the mass-mediated marketplace. Finally, the pair also recommended that in the era of globalization of consumer culture, one must examine how consumer culture is evolving in non-developed countries. Other CCT researchers [9]-[10]-[11] have also set out to measure this phenomenon. In developing countries, local consumer culture is increasingly shifted and altered by global consumer culture [12]

CCT research topics in the context of consumer globalism [3] and consumer nationalism [13] have attracted increasing numbers of CCT researchers. International-marketing researchers focus on consumer predispositions towards foreign or local products and brands, which are the manifestations of socio-psychological and socio-cultural worlds. Products and brands are seen as agents of marketplace phenomena, i.e. as carriers of identities and meanings that are social, personal, and cultural. Consumer globalism and nationalism predispose consumers to foreign or local products and brands, respectively. Given the ongoing nature of the globalization phenomenon, scholarly knowledge on such predispositions is still expanding, and it merits further investigation. To that end, this paper explores the issue of consumers' foreign vs local predispositions to identify new research directions. 


\section{METHODS}

This essay reviews the literature on the concepts of teacher competence and research findings on Indonesian teachers' competence. The concept of teacher competence in the time of pandemic is formulated by referring to the concept of competence from the perspective of critical English pedagogy, both from Indonesian and Western perspectives. The two conflicting concepts on teachers' competence evaluation (standardized versus contextualized competencies) are also discussed by referring to at least 35 research papers on the subject matter. These works of literature are then linked to the pandemic situations to suggest considerations for selecting one of the three options.

\section{RESULT AND DISCUSSION}

Various theoretical explanations of predisposition towards foreign or local products and brands have been set forth. [14] argued that predisposition is primarily explained by five relevant theories: social identity theory, personal identity theory, cultural identity theory, system justification theory, and categorical cognition theory. A discussion of these individual theories is laid out below to facilitate the author's identification of the research questions of each. This also enables the identification of interesting questions that are related to more than one single theory.

\section{A. Social identity theory}

Social identity theory provides that in-group favoritism emerges from the intrinsic need to maintain a positive social identity and positively differentiate the in-group from outgroups [14]. Consumer ethnocentrism (CET) is the predominant construct of this theory. Describing individuals' beliefs that their groups are superior and the 'center of the universe, it relates to consumers' convictions regarding the appropriateness, and indeed the morality, of purchasing foreign products vs local ones [15]. Accordingly, highly ethnocentric consumers, for the good of the national economy, behave more favorably towards domestically made products. They may ignore rational considerations and overestimate the quality of locally made products [16] as a function of their sense of national belonging. Such consumers identify strongly with their own country and tend to reject the idea of consuming imported products. Regarding consumer predisposition towards local vs foreign brands, [17] propose a construct rooted in CET: local brand consciousness. Local brand consciousness refers to consumer attention dedicated to supporting local brands rather than foreign ones; it is seen as a realization of one's pride, love, and sense of obligation towards one's own country. Consumers with strong local brand consciousness behave positively towards local brands and, because of their understanding of buying local as a civic duty, exhibit strong preferences for those brands in comparison with global ones. This reflects the desire of domestic consumers to protect local brands and their national identity [18], they involve actively in consuming, using, buying, or wearing local brands.

Karoui and Khemakhem [11] argued that the effect of CET on consumer willingness to buy local products/brands tends to be stronger in developed countries than in developing ones. Nonetheless, they also wrote that previous studies in developing countries yielded inconsistent findings on the issue. In Indonesia, for instance, [19] found that young consumers in Jakarta are less ethnocentric and demonstrate no impact of foreignness/localness on willingness to buy. In contrast, [16], in a study in Mataram, found a significant effect of CET on young consumers' willingness to buy locally made products. Furthermore, in a nationwide study, [20] arrived at an intriguing yet contradictory finding: that while ethnocentric consumers tend to have open minds towards global citizenship, their acceptance of global cultural forces does not include the abandonment of local culture. The researchers argued that the political economy has transformed Indonesian consumers. Accordingly, [13] suggested that CET is triggered by political and economic nationalism, especially in developing countries. Such countries' governments sometimes have unstable political and economic policies, and differences in political and economic policies, wisdom, and priorities may establish a foundation for stronger or weaker CET. A country's political and economic dynamics over time are highly likely to determine the state of CET in that countries, and therefore, it is important to explore sociohistorical, political, and economic influences on consumer perceptions of their group (nation) and how they manifest in consumption of foreign vs local brands and products.

\section{B. Personal identity theory}

Personal identity theory differs from social identity theory concerning its focus. Personal identity theory centers on consumer roles, which shape consumer identity and behavior. Social identity theory, in contrast, centers on groups and intergroup aspects of behavior. Personal identity theory explains that consumers align their behavior with their role (identity) to avoid incongruence between their identity and their perceptions at the hands of others [14]. Each desires a personal identity with which to build their status and establish their roles in life, and possessing or consuming certain products and brands is a means of developing such an identity. Some popular constructs in this theory are consumers' cosmopolitanism and the need for uniqueness.

Consumer cosmopolitanism is a consumer orientation governing the extent to which consumers are open-minded towards foreign countries and cultures [14]. Consumers with a strong orientation towards cosmopolitanism exhibit a greater willingness to buy foreign products and brands than domestic ones. Consumers in developing countries often believe that globalization is a modern civilization; they tend to support, enjoy and follow global (foreign) products and brands, evidencing their global orientation [21]. Globalization brings global products and brands to developing countries where consumers view global products and brands as more favorable than local ones. Even so, according to [13], consumer cosmopolitanism can coexist with - and even depends on consumer nationalism. Consumers may engage in cosmopolitan behavior but also maintain favorable attitudes towards local products and brands. This suggests an interplay between consumer globalism and nationalism, and such an interplay ought to be the subject of future research.

The consumer's need for uniqueness manifests as a need to express his or her identity through the choice of a brand that they perceive as special, unique, rarely owned by others, and usable to signal a unique self-image and support one's lifestyle [17]. Consumers seek out brands that have unique characteristics [5], and foreign brands, which are usually more 
expensive and not owned by most consumers, are seen as capable of demonstrating personal identity. Consumers with pronounced needs for uniqueness enhance their self-image by emphasizing and showcasing their ownership of products and brands that are considered original, special, or unique. Accordingly, such consumers tend to be strongly materialistic. Conversely, local brands and products are mostly owned by domestic consumers and thus are seen as not giving the impression of being special, luxurious, or unique. Consumers who perceive a strong need for uniqueness are not interested in local brands. They are attracted to foreign/global brands that tend to be subject to limited availability and are thus not owned by most consumers, and they tend to express avoidance or even hatred of local brands. Regarding brand hate, [22] stated that local consumers are more likely to demonstrate passive hatred, rather than active hatred, toward local brands. Nevertheless, whether passive hate toward local brands exists and is consistent across the spectrum of functional (utilitarian) and hedonic (conspicuous) products continues to bear investigating.

\section{Cultural identity theory}

Cultural identity theory is the primary conceptual basis of local and global identities. It explains how individuals identify themselves as local or global citizens. This theory can be situated between the above theories of personal and social identity as it involves both group and individual identities [14]. Consumer attitudes toward foreign vs local products and brands have received constant attention from international marketing researchers seeking to explain global vs local consumer cultures. Based on the work of [8], [12, p. 3] proposed the following definition of global/local culture: 'social arrangements in which the relations between lived culture and social resources, and between meaningful ways of life and the symbolic and material resources on which they depend, are globally (locally) conceived and are mediated through deterritorialized, global (geographically anchored), local markets'. This suggests that consumption, in a given socio-cultural context, is shaped by dynamic market forces i.e. globalism, localism, or both.

Since CCT covers the effects of both group identities and individual identities on consumption acts, the consumption of products and brands is an expression of both one's social (group) identity and self-identity in CCT. Products and brands are symbols in consumers' lives; they are viewed as the sources of symbolic meaning. When consumers live out a global consumer culture, they will behave more favorably towards products and brands rich in global symbolic meanings, and they will behave oppositely when they adhere to local consumer culture. [23] proposed global symbolicvalue orientation to refer to the tendency or desire of consumers to obtain symbols that strengthen the image of their global citizenship. Consumers with strong orientations of this type will act on strong desires to possess brands that symbolize global consumer culture. They crave symbolic values such as social status, wealthy appearance, success, prestige, uniqueness, and luxury. Consumers believe that these values are inherent in global/foreign brands, particularly those that come from Western (developed) countries, and in developing nations, consumers have a strong tendency to seek out symbolic value in global brands. However, consumers today live simultaneously in both global and local cultures [12]. Therefore, it is critical to understand the dynamic interplay between nationalism and globalism in developing countries and the consequences of the interplay. Additionally, further investigations shall be focused on the rise of glocal brands in developing countries, as prior studies tend to uncover the trend in developed nations [24].

\section{System justification theory}

This theory stands in contrast to social identity theory. It explains that members of groups that are low in social and material standing exhibit in-group derogation and out-group favoritism [14]. System justification theory predicts that consumers will tend to favor products and brands from other countries - especially those from more developed nations - as they view those countries are superior to their own. Consumer xenocentrism (C-Xen) is the primary construct of this theory. It refers to a consumer's internalized belief of the inferiority of domestic products and their corresponding propensity to prefer foreign products for social the purpose of aggrandizement [25]. CET seems to be the opposite of consumer xenocentrism; however, it is important to recall that the two hail from different theories. CET arises in social identity theory, which predicts that consumers in developing countries will exhibit negative behavior towards brands or products from other countries, regardless of the level of economic development in the country of origin. C-Xen appears in system justification theory, which explains the importance of relative differences in status between countries - less developed, developing, and developed countries, for example. Consumers from countries with comparatively low status (i.e. developing ones) are more likely to exhibit xenocentric tendencies than consumers from higher-status (i.e. developed) countries [25]. Consumers in low-status countries justify the purchase of products or brands from higher-status countries simply by asserting that they are better and more worthy of admiration. They readily conclude that good products and brands must come from abroad. Such consumers have positive general impressions of foreign products and brands, which suggests a strong and favorable halo effect on those products and brands [26].

High-quality local products and brands are available in developing countries [18]-[27]. However, the favorable identities attached to these local products and brands may lead local consumers to misclassify them as foreign [28]. Local consumers do not expect strong local brands to exist in the domestic market, and they are prone to assuming that all favored brands available on the domestic market come from other (more developed) countries. This mistaken attribution suggests that local consumers are unable to accurately identify local brands. Such misclassification plays a significant role in governing attitudes towards brands [26] as consumers' attitudes are directly influenced by their knowledge - correct or otherwise - of a brand's country of origin. It is therefore reasonable to assume that a consumer's misidentification of strong local brands as foreign is also indicative of a negative attitude towards brands recognized by that consumer as local.

Consumers in developing countries are foreign-brand admirers: they perceive foreign brands to offer high quality and high emotional value [22]. Consumers may not be intimately familiar with foreign brands, but they nevertheless approach those brands with pre-existing favorable perceptions of their quality [25]. Such consumers evaluate the brands as able to fulfill their desires. This perception may not always 
stem from consumers' own experiences; rather, they admire a given brand because they perceive it as offering what the consumer truly desires. Brand admiration can still be held by consumers who do not necessarily experience satisfaction from using or perceive any particular excellence of, the brand. Conversely, these consumers lack pride in local brands, which are perceived as inferior to foreign ones [18]. This inferiority complex engenders negative emotion towards local brands, whose perceived low quality and low prestige will reduce the social respect afforded to their users. This attitude is widely shared by consumers in developing countries, owing to a pervasive colonial mentality felt by domestic consumers that trigger feelings of inferiority [11]. The age of colonialism has long since ended, but its effects have not; feelings of national inferiority are unconsciously propagated from one generation to the next, even in the era of globalization, and they influence consumer predispositions toward foreign brands and products over local ones. However, given that such feelings pass from generation to generation, generational differences may exist in the level of xenocentrism and degree of inability to identify local brands. The possible existence of these differences requires. It is similarly important to uncover differences in these constructs' impacts on behavior towards foreign and local products and brands.

\section{E. Categorical cognition theory.}

The country of origin effect (COO) is the primary construct of this theory, which explains that consumers rely on categorical representations of the world to economize their cognitive resources and streamline their cognitive process [29]. This concept focuses on the fit between countries and product categories, and it explains how consumer behavior towards product categories depends on the image of the source country. A country with a positive reputation concerning certain product categories will enjoy favorable consumer behavior in international markets; as expected, negative reputations will result in just the opposite. However, according to [9], studies on COO have been described as stagnant, and the research stream must be renewed by investigating the contexts of new market countries, e.g., developing countries, where consumers' socio-psychological characteristics (such as consumer affinity, consumer animosity, etc.) may interact with socio-cultural (e.g., religious) beliefs and affect real consumer behavior. Furthermore, previous studies on $\mathrm{COO}$ have primarily focused on the image of the foreign countries from which the imported products come and how that image may explain consumer behavior. Studies about the image of the home country, and how it influences the behavior of domestic consumers, remain limited. More precisely, little is known about the role of home-country image in consumers' evaluation behavior and purchase behavior in developing countries [16]. Furthermore, another fundamental gap remains in the multi-dimensionality of country image [9], particularly in assessing consumers' home countries in an emerging market [16]. Therefore, investigations of the country image may not focus solely on how consumers perceive other countries and behave towards imported products but also on how domestic consumers' perceptions of their own country, across various characteristics, affect how they behave towards domestic products.

Research on $\mathrm{COO}$ has shifted from product origin to brand origin, which is considered more relevant in today's international marketing practice and has greater influences on CB. Nonetheless, consumers in developing countries are often confused and misapprehend the nationalities of famous brands. Indeed, they may be unable to distinguish between local and foreign brands [30]-[26]. This misapprehension occurs particularly often with famous local brands and is caused by the halo effect of (favorable) foreign countries and the perceived inferiority of local products and one's home country [28]. Domestic consumers lack knowledge of local brand origins and exhibit favorable behavior towards brands that they (missed)perceive as originating in favorable countries. Why consumers in developing countries underestimate their country's capability to develop highquality products and brands is deserving of understanding and, as such, demands study.

According to [14], the above theories vary in terms of the influence of their central constructs on consumer attitudes and loyalty. These variations depend on the product category, the type of consumption (conspicuous vs inconspicuous), and the nature of the product (hedonic vs functional). The phenomena of conspicuous consumption and hedonic purchasing are made strong in developing countries by wide economic disparities. Constructs in each theory will have impacts on consumers' predispositions towards foreign or local products and brands, depending on their images of the $\mathrm{COO}$ and their own country. Consumers in developing countries tend to view certain products and brands from favorably perceived (developed) countries as prestigious or luxurious and thus behave favorably towards those products and brands even if they possess ethnocentric tendencies [11] - [20]. Xenocentrism is triggered by consumers' images of the source country and their own country [14], and because some brands come from favorable countries, consumers may pursue certain global symbolic values through those brands [22]. Nonetheless, global brands such as 7-Eleven have been defeated by local retailers in Indonesia; a similar story unfolded for McDonald's and Burger King in the Philippines and Vietnam. Thus, it remains to be asked whether consumers who discover that they have strong local brands will perceive their country more positively or feel less inferior. Furthermore, that local brands are perceived as lacking symbolic value and thus avoided or (passively) hated causes another question to emerge: can passive brand hate be reduced by domestic consumers' improved images of their own country or by their local brand knowledge?

Three studies share a similar view: that consumers in developing countries can live simultaneously in local and global consumer culture, depending on the situations those consumers face [12], [13], [20]. However, it is far from clear how the combination of cultures can stably develop in consumer life, particularly in today's hyperconnected world. The recent and rapid growth of information technology has facilitated consumer interactions that transcend geographical boundaries, strengthening global citizenship. Consumers now enjoy wider opportunities to interact, through social media, with individuals anywhere and everywhere. They can share thoughts, opinions, feelings, experiences, and even hopes. This interaction social media-based can reinforce certain trends - those that remove consumers from local consumer culture and immerse them even more deeply in global consumer culture, and those that do the opposite. 
The need to study consumption communities, and especially brand communities, in greater depth [3]-[8]. The internet is accelerating the formation of consumption communities, which are likely to reach a global scale. Brand communities are facilitated by social media, which, by enabling consumers to socialize and form groups of likewisethinking individuals, allows the formation of this new subculture. Symbolic values are produced by individual consumers and their social groups, who also define their meaning. Indeed, the symbols attached to products and brands would be meaningless without consumers' social interactions. Social interactions may lead to homogeneity in consumers' societies. Brands, then, are shared ownerships in which consumers co-create brand experiences and brand meaning, evidencing a blurring of brand boundaries [31]. Online brand communities are communities in which every member can engage in online conversation, through which brand meanings are dynamically co-created, reshaped, or reinvented. Consumers participate online in the co-creation of brand meanings, making brand communities participatory experiences. Members of such communities develop traditions, rituals, and even a sense of shared culture [32]. They share a common interest in, and loyalty to, the brand, which unifies them in dynamic and iterative actions (dialogues and interactions) on the internet. However, the questions arise: do consumers tend to desire involvement in global brand communities across countries when they are also attached to the local culture? and how is symbolic meaning created through social media? Online brand communities seem to play important roles in strengthening global consumer culture in developing countries, making these two questions areas of significant interest for further research. Moreover, technological development also allows for the rapid development of e-commerce in developing countries where strong local brands emerge, but share ownership may not be limited to one country of origin. Future research needs to explore whether ownership influences $\mathrm{CB}$ in developing countries.

Last but not least, the COVID-19 pandemic provides another interesting research context. The pandemic is currently projected to last quite some time, and no party can confidently predict when it will end. What is certain, however, is that this pandemic is affecting CB and that these effects will persist after the pandemic is concluded. It is quite possible that as the pandemic grows longer, its impact on $\mathrm{CB}$ grows even more profound. Future research will need to focus on how this pandemic has changed (and continues to change) consumers' predispositions towards foreign vs local products and brands.

Since the pandemic, consumption of certain products has increased. Examples of such products include bicycles, plants, and gardening tools. Consumers seem to be making more ethical and environmentally friendly purchases, but they also demonstrate a high degree of materialism: this consumption is quite conspicuous, and consumers buy such products even though their prices are far above normal. Moreover, the tendency of ethnocentrism drives group consciousness and feelings of cooperative energy and empathy to support consumers' social groups [33]. This was evident when the COVID-19 pandemic hit Indonesia: calls were made in the media, including on social media, for consumers to buy at small stalls in their communities to help those businesses survive the economic recession. This local purchasing behavior benefits the nation on economic, social (community), and environmental levels. Though buying local is sometimes considered to overlap with green consumerism, [34] argued that consumers with low incomes and poor educations - which are the typical characteristics of consumers in developing countries - are motivated to buy local for social and economic benefits but not necessarily out of environment concern. [35] reported that consumers in developing countries that have a strong global culture trend strongly towards materialistic and environmental values. They prefer environmentally friendly products with global brands, which they see as more environmentally friendly. These products are sold at high prices but, at the same time, reflect the consumer's materialistic tendency. Further research needs to explore the issues. Furthermore, the current pandemic has raised Indonesian consumers' health consciousness and encouraged a tradition of maintaining health by consuming local herbal and organic medicine (jати). This reflects a return by consumers to the local culture, which raises the question: can this pandemic strengthen local culture and reduce the impact of global consumer culture? Or can this increased purchasing of local medicinal herbs simply be attributed to their affordability and relative ease of access in a time of economic recession? A final area worthy of investigation is how young consumers, who grew up in the era of market globalization and live in a global culture, have behaved towards traditional herbal medicine during the pandemic.

\section{CONCLUSION}

This paper's explorations of various theories and constructs of consumer behavior identify several prospective research questions that may guide future research directions. These questions and directions were identified by critical examinations of each theory and consideration of novel contexts in the study of consumer culture. The author hopes that these research avenues will lead to studies of each theory that are sharper, deeper, and more focused but also permit the integration of knowledge from adjoining disciplines (politics, economics, history, etc.) to the study of consumer culture. This shall lead to a deeper, better understanding of consumer predispositions between foreign and local products and brands.

\section{ACKNOWLEDGMENT}

The author acknowledges Miss Kyle (Cambridge Proofreading \& Editing Services LLC) for kindly proofreading the paper.

\section{REFERENCES}

[1] L. A. Peracchio, F. Luce, and A. L. McGill, A.L "Building Bridges For an Interconnected Filed of Consumer Research", Journal of Consumer Research, vol. 40, no., pp v-viii, 2014.

[2] D.J. Macinnis, \& V.S. Folkes, "The disimplinary status of consumer behavior: A sociology of science perspective on key controversies", Journal of Consumer Research, 2010, DOI: 10.1086/644610

[3] R. Belk, "The Wiley Blackwell Encyclopedia of Consumption and Consumer Studies", First edition, edited by Daniel Thomas Cook and J. Michael Ryan, John Wiley \& Son, 2015.

[4] E. Illouz, "Emotion, Imagination and Consumption", Journal of Consumer Culture, vol 9 no 3, pp. 377-413, 2009. 
[5] J. Sihvonen, Understanding the drivers of consumers-brand identification, J. Brand Manag, 2019, https://doi.org/10.1057/s41262018-00149-Z

[6] J. Huber, W. Kamakura, W. and C.F. Mela, "A topical history of JMR", Journal of Marketing Research, L.I, (February), pp. 84-91, 2014

[7] X. Wang, N.T. Bendle, F. Mai, and J. Cotte, "The Journal of Consumer Research at 40: a historical analysis, Journal of Consumer Research, 42, 2015, DOI: 10.1093/jcr/ucv009

[8] E.J. Arnould, E. J., and C.J. Thompson, "Consumer culture theory (CCT): Twenty years of research". Journal of Consumer Research, vol. 31, pp. 868-882. 2005

[9] I. R. Lu, L.A. Heslop, D.R. Thomas, and E. Kwan, “An Examination of the Status and Evolution of Country Image Research," International Marketing Review, vol. 33, no 6, 825-50. 2016

[10] W. Tangsupwattana, and X. Liu, X. "Symbolic consumption and Generation Y consumers evidence from Thailand, Asia Pacific Journal of Marketing and Logistics, vol 29, no 5: pp. 917-932. 2017

[11] S. Karoui, and R. Khemakhem, R. "Consumer ethnocentrism in developing countries", European Research on Management and Business Economics, vol 25, pp. 63-71. 2019

[12] J.E.M. Steenkamp, "Global Versus Local Consumer Culture: Theory, Measurement, and Future Research Directions", Journal of International Marketing, pp.1-19 2019. DOI: $10.1177 / 1069031 X 18811289$

[13] E. Castelló, and S. Mihelj, "Selling and consuming the nation Understanding consumer nationalism. Journal of Consumer Culture, vol. 18, pp. 558-576. 2017 https://doi.org/10.1177/1469540517690570

[14] G. Balabanis, A.Stathopoulou, and J. Qiao, J. "Favoritism toward Foreign and Domestic Brands: A Comparison of Different Theoretical Explanations". Journal of International Marketing, 2019. 1069031X19837945. 26.

[15] T. Shimp. and S. Sharma, "Consumer ethnocentrism: construction and validation of the CETSCALE", Journal of Marketing Research, vol. XXIV, pp.280-289. 1987

[16] Sulhaini. "Home country image and ethnocentrism among young consumers in a developing country". Journal for Global Busines Advancement, vol. 9 no 2, pp.: 195 - 211.2016

[17] Sulhaini, Rusdan, Sulaimiah and R. Dayani, The effect of Local Brand Consciousness and Need for Uniqueness towards emotional value and buying intention on local brands, Majalah Bisnis, vol.19, no 1, 2020a, https:doi.org/10.24123/jmb.v19i1

[18] X. Zhu, C. Yu., and S. Hu, "Love for one's country or oneself: A brandchoice framework in emerging markets", Social Behavior and Personality, vol.44, no. 2, pp. 325-338. 2016

[19] E. Purwanto, "The Effect of consumer ethnocentrism on perceived domestic product quality and purchase intentions among young consumers in Jakarta, Indonesia", International Journal of Asian Social Science, vol 4, no. 9, pp. 1003-1012. 2014

[20] A.H. Pratono, and D. Arli, "Linking global consumer culture and ethnocentric consumerism to global citizenship: exploring the mediating effect of cultural intelligence", International Journal of Sociology and Social Policy, vol. 40, no 7/8, pp. 659-675, 2020.

[21] Sulhaini, R. Dayani, Rusdan and Sulaimiah, "Consumer Global Orientation and Its Impact on Consumer's positive emotion", International Research Journal Of Business Studies, vol. 11, no 2, pp. 81-92, https://doi.org/10.21632/irjbs.11.2.81-92. 2018
22] Suhaini, Sulaimiah and J. Sagir, "Young Consumers in An Asian Developing Country: are they foreign brand admirers or haters? International Research Journal for Business Studies, vol. 13, no 1, pp, 33-47 2020b

[23] Sulhaini, Rusdan, Sulaimiah dan R. Dayani, "Pengaruh symbolic value dominance dan subjective knowledge terhadap Sikap dan e-WOM merek lokal, 2020c; Laporan Hasil Penelitian FEB UNRAM.

[24] M.A. Lopez-Lomelí, J. Llonch-Andreu, and J.,Rialp-Criado, "Local, global and glocal consumer brand relationships, Spanish Journal of Marketing, vol. 23, no 3, pp. 437-459 2019.

[25] A. Balabanis, and A. Diamantopoulos, "A, Consumer, Xenocentrism as Determinant of Foreign Product Preference: A System Justification Perspective", Journal of International Marketing, vol. 24, pp. 58-77. 2016

[26] Sulhaini, B.H. Rinuastuti, and D.P.B. Sakti, "The halo effect of foreign brands on the misclassification of local brands, Management \& Marketing. Challenges for the Knowledge Society, vol.14, no. 4: 357371, 2019a.

[27] M.S. Rahman, and M. Mannan, "Consumer online purchase behavior of local fashion clothing brands: Information adoption, e-WOM, online brand familiarity and online brand experience", Journal of Fashion Marketing and Management: An International Journal, 2018. https://doi.org/10.1108/JFMM-11-2017-0118

[28] Sulhaini, Rusdan, R. Dayani, Sulaimiah, and B. Ismiwati, "Local brand origin knowledge of young consumers in a developing country", Int. Journal of Applied Management Science, vol. 1,1 no.1): 72-90, 2019b

[29] C.N. Macrae, and G.V. Bodenhausen, G. V. "Stereotypes. In S. T. Fiske, D. L. Schacter, \& C. Zahn-Waxler (Eds.), Annual review of psychology (Vol. 51, pp. 93-120). Palo Alto, CA: Annual Reviews, 2000

[30] Sullhaini, and J. Sagir. "Identifying Interesting Themes Regarding Country of Origin Effect: A Preliminary Study". Proceeding of the 12th UBAYA International Annual Symposiun on Management Makassar Indonesia, pp 892 - 906. 2015

[31] V.A. Swaminathan, J. Sorescu, J.E.M. Steenkamp, T.C., O'Guinn, \& B. Schmitt. "Branding in a hyperconnected world: Refocusing theories and rethinking boundaries". Journal of Marketing, vol. 84, no. 2. pp 24-46. 2020.

[32] J. Burgess, and C. Jones, "Exploring the forced closure of a brand community that is also a participatory culture", European Journal of Marketing, vol 54, no 5, pp, 957-978.2020

[33] H. El Jurdi and R. Houjeir, "Cultural norms and the marketplace: favor economies in the Arab world", Journal of Consumer Marketing, vol. 37, n 2, pp.,226-235.2020

[34] E.D. Schoolman, "Building community, benefiting neighbors: "buying local" by people who do not fit the mold for "ethical consumers" Journal of consumer culture, 2017. https://doi.org/10.1177\%2F1469540517717776

[35] Y. Strizhakova, Y. and R.A. Coulter, 'The 'green' side of materialism in emerging BRIC and developed markets: The moderating role of global cultural identity". International Journal of Research in Marketing, vol. 30 no. 1, pp: 69-82, 2013. 